\title{
Valvuloplasti Balon Transkateter Perkutan pada Neonatus dengan Stenosis Pulmonal Kritis
}

\author{
Herlina Dimiati, ${ }^{*}$ Mulyadi M. Djer**, Maswin Masyhur*** \\ * Bagian Ilmu Kesehatan Anak, Fakultas Kedokteran Unsyiah / RSU Zainal Abidin Banda Aceh \\ ** Divisi Kardiologi Departemen Ilmu Kesehatan Anak, Fakultas Kedokteran Universitas Indonesia, RS \\ Dr. Ciptomangunkusumo Jakarta \\ ***Departemen Ilmu Kesehatan Anak Fakultas Kedokteran Universitas Indonesia, RS Dr. Ciptomangun \\ kusumo Jakarta
}

\begin{abstract}
Valvuloplasti balon transkateter perkutan/percutaneous transcatheter balloon valvuloplasty (PTBV) pada stenosis pulmonal adalah tindakan non bedah untuk mengatasi obstruksi jalan keluar dan mengurangi beban sistolik ventrikel kanan akibat stenosis katup pulmonal dengan menggunakan balon. Metode ini merupakan kardiologi intervensi yang telah berkembang pesat menggantikan peran bedah dalam penanganan penyakit jantung bawaan dengan menawarkan beberapa keuntungan, antara lain: berkurangnya waktu perawatan dan biaya perawatan, alasan kosmetik (tidak menimbulkan jaringan parut di dada) serta kurang invasif. Dilaporkan seorang bayi laki-laki berumur 2 hari, dirawat di Pelayanan Jantung Terpadu Rumah Sakit Dr. Cipto Mangunkusumo (RSCM) dengan stenosis pulmonal kritis (SPK), defek septum atrium (DSA) sekundum sedang dengan pirau kanan ke kiri dan duktus arteriosus persisten (DAP) sedang yang panjang. Tindakan percutaneus transcatheter balloon valvuloplasty (PTBV) harus dilakukan secepatnya untuk menyelamatkan jiwa pasien. (Sari Pediatri 2007; 9(4):246-51).
\end{abstract}

Kata kunci: intervensi kardiologi, percutaneus transcatheter balloon valvuloplasty (PTBV), stenosis pulmonal kritis $(\mathrm{SPK})$

\footnotetext{
Alamat korespondensi

Dr. Herlina Dimiati, SpA, Dr. Mulyadi M.Djer, SpAK

Divisi Kardiologi Departemen Ilmu Kesehatan Anak FKUI-RSCM

Jl. Salemba No 6 Jakarta 10430Telpon: 021-39225901

Dr. Maswin Masyhur PPDS Departemen Ilmu Kesehatan Anak

FKUI-RSCM Jl. Salemba No 6 Jakarta 10430 Telpon: 021- 7443616
}

$\mathrm{V}$ alvuloplasti balon transkateter perkutan/ percutaneous transcatheter balloon valvuloplasty (PTBV) pada stenosis pulmonal adalah tindakan non bedah untuk mengatasi obstruksi jalan keluar dan mengurangi beban sistolik ventrikel kanan akibat stenosis katup pulmonal dengan menggunakan balon. ${ }^{1}$ Metode 
ini berkembang sejalan dengan berkembangnya intervensi kardiologi dan menawarkan beberapa keuntungan dibandingkan operasi, antara lain menghindari torakotomi dan jaringan parut di dada, berkurangnya lama rawat dan biaya perawatan di rumah sakit. $^{2}$

Stenosis pulmonal kritis (SPK) merupakan stenosis pulmonal berat terjadi pada neonatus yang menyebabkan obstruksi jalan keluar ventrikel kanan atau aliran ke arteri pulmonalis yang memerlukan intervensi dini. ${ }^{1}$ Obstruksi ini terjadi karena fusi daun katup pulmonal sehingga katup berbentuk kerucut dengan jaringan fibrosa di tengah atau dapat juga berupa lubang yang lebih kecil dari annulus pulmonal. $^{3}$

Stenosis pulmonal kritis merupakan salah satu penyakit jantung bawaan (PJB) yang menyebabkan sianosis pada bayi baru lahir dan berpotensi menyebabkan kematian. Aliran darah paru pada neonatus dengan SPK tergantung pada ada tidaknya duktus arteriosus persisten (DAP). ${ }^{3-5}$ Stenosis pulmonal kritis jarang terjadi, diperkirakan prevalensi sekitar 0,58 per 10.000 kelahiran hidup. ${ }^{6}$

Berikut ini dilaporkan satu kasus Stenosis pulmonal kritis (SPK) dan dilakukan tindakan percutaneous transcatheter balloon valvuloplasty (PTBV) yang pertama kali dilakukan di Indonesia untuk menyelamatkan jiwa pasien.

\section{Kasus}

Seorang bayi, laki-laki, usia 2 hari dirujuk oleh dokter spesialis anak konsultan untuk dilakukan tindakan PTBV. Alloanamnesis dari orangtua didapatkan keterangan bayi lahir cukup bulan dengan bedah kaisar atas indikasi bayi besar, detak jantung yang tidak teratur. Berat lahir 4200 gram dan panjang lahir $55 \mathrm{~cm}$ segera menangis. Setelah lahir bayi tidak sesak, namun jika menangis bayi tampak biru. Pada pemeriksaan fisis terdengar bising ejeksi sistolik di sela iga-2 garis parasternal kiri. Dilakukan pemeriksaan ekokardiografi dengan kesimpulan stenosis pulmonal kritis (SPK), defek septum atrium sekundum sedang dengan pirau kanan ke kiri dan duktus arteriosus persisten sedang yang panjang. Disarankan untuk dilakukan percutaneus transcatheter balloon valvuloplasty (PTBV) secepatnya untuk menyelamatkan jiwa pasien.
Riwayat kehamilan ibu, pemeriksaan kehamilan teratur oleh dokter ahli kebidanan, tidak dijumpai keputihan, demam dan infeksi saluran kemih. Tidak ada riwayat keluarga dengan kelainan jantung, hipertensi dan diabetes melitus. Pasien merupakan anak ketiga dari tiga bersaudara, saudara kandung dan kedua orangtua pasien sehat.

Pada pemeriksaan fisis tanggal 4 April 2007 didapatkan bayi tampak sehat, tidak letargis maupun sesak, namun tampak sianosis ringan. Berat badan $4200 \mathrm{~g}\left(\mathrm{P}_{90-97}\right.$ NCHS-CDC 2000), tinggi badan 55 $\mathrm{cm}\left(\mathrm{P}_{97}\right.$ NCHS-CDC 2000). Tekanan darah sistolik $85 \mathrm{mmHg}$, tekanan darah diastolik $40 \mathrm{mmHg}$. Laju nadi sama dengan laju denyut jantung 133 kali per menit, teratur, isi nadi cukup, laju napas 40 kali per menit, teratur, kedalaman cukup, tidak tampak retraksi, suhu $37^{\circ} \mathrm{C}$.

Pada pemeriksaan kepala tidak didapatkan deformitas, ubun-ubun besar terbuka, datar, lingkar kepala $35 \mathrm{~cm}$ (normal). Pada wajah tidak ditemukan dismorfisme, pemeriksaan fungsi nervus kranialis normal. Mata didapatkan konjungtiva tidak pucat, sklera tidak ikterik, pupil bulat isokor, diameter $2 \mathrm{~mm}$, refleks cahaya $+/+$. Pemeriksaan telinga, hidung dan tenggorok tidak ditemukan kelainan. Mulut dan mukosa lidah sianosis ringan. Kelenjar getah bening tidak membesar. Pemeriksaan dada tampak simetris. Bunyi jantung I normal, bunyi jantung II tunggal, terdengar bising ejeksi sistolik derajat 3 dari 6 skala pada sela iga - 2 garis sternal kiri, tidak terdengar irama derap. Suara napas vesikular, tidak terdengar ronki maupun mengi. Perut lemas, turgor cukup, hati dan limpa tidak teraba. Pada pemeriksaan anggota gerak didapatkan akral hangat, perfusi perifer baik.

Hasil pemeriksaan darah tepi, kadar hemoglobin $18,3 \mathrm{~g} / \mathrm{dL}$, hematokrit $51,3 \mathrm{vol} \%$, leukosit $10.900 /$ $\mathrm{mL}$, trombosit $297.000 / \mathrm{mL}$. Analisis gas darah $\mathrm{pH}$ 7,42 $\mathrm{pCO}_{2} 34,5 \mathrm{mmHg}, \mathrm{pO}_{2} 88,2 \mathrm{mmHg}, \mathrm{HCO}_{3}^{-}$ $22,9 \mathrm{mmol} / \mathrm{L}, \mathrm{BE}-1,7 \mathrm{mmol} / \mathrm{L}, \mathrm{SO}_{2} \% 97,9$. Pemeriksaan elektrolit $\mathrm{Na}^{+} 133,3 \mathrm{mmol} / \mathrm{L}, \mathrm{K}^{+} 3,79$ $\mathrm{mmol} / \mathrm{L}, \mathrm{Cl}^{-} 105 \mathrm{mmol} / \mathrm{L}$. Pada pemeriksaan foto radiologik toraks didapatkan kardiomegali. Pada pemeriksaan EKG didapatkan irama sinus, laju QRS $125 \mathrm{x} / \mathrm{menit}$, axis QRS $135^{\circ}$, P pulmonal di lead II dilatasi atrium kanan (RAE) dan hipertrofi ventrikel kanan (RVH). Ekokardiografi memperlihatkan SPK dengan pressure gradient (PG) $81 \mathrm{mmHg}$, DSA sekundum sedang dengan pirau kanan ke kiri dan DAP sedang yang panjang. 



Gambar 1. Dooming katup pulmonal dan turbulensi aliran di katup pulmomal pada pandangan subkostal 2 dimensi dan Doppler warna

Diagnosis kerja pada saat itu stenosis pulmonal kritis (SPK), DSA sekundum sedang, DAP sedang yang panjang. Bayi direncanakan untuk dilakukan PTBV keesokan hari. Hasil kateterisasi ditemukan stenosis pulmonal dengan PG $81 \mathrm{mmHg}$. Katup pulmonal mula-mula ditembus dengan wire koroner ukuran 0,014 inci, kemudian melalui wire ini dimasukkan balon koroner ukuran $2 \mathrm{~mm}$, lalu balon dikembangkan. Selanjutnya balon koroner $2 \mathrm{~mm}$

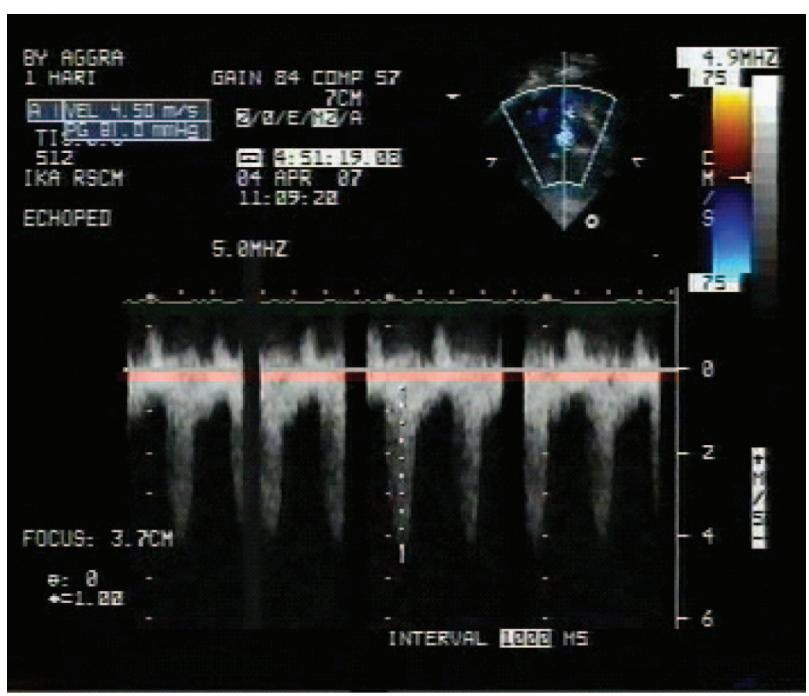

Gambar 2. Pressure gradient $81,0 \mathrm{mmHg}$ di katup pulmonal pada pandangan subkostal Doppler continuous wave diganti dengan balon koroner $4 \mathrm{~mm}$, balon dikembangkan dengan cara yang sama. Akhirnya katup pulmonal dilebarkan dengan balon Thysak ukuran 8 $\mathrm{mm}$, balon dikembangkan sebanyak 3 kali. Waktu dilakukan pengukuran pasca balon, masih ditemukan PG $45 \mathrm{mmHg}$. Saat prosedur terdapat beberapa episode desaturasi yang bersifat sementara. Pasca PTBV tidak ditemukan perdarahan di inguinal kiri dan kanan, denyut arteri dorsalis pedis kiri dan kanan baik. Pasca PTBV bayi dirawat di ICU PJT untuk dimonitor selama 24 jam. Pengobatan yang diberikan pasca tindakan adalah seftriakson IV $100 \mathrm{mg} / 12 \mathrm{jam}$, alprostadil 10 nanogram $/ \mathrm{kgBB} /$ menit, dopamin 5 mikrogram $/ \mathrm{kgBB} /$ menit, nitrogliserin 10 mikrogram/ $\mathrm{kgBB} /$ menit. Pasca PTBV hemoglobin $12,6 \mathrm{~g} / \mathrm{dL}$, hematokrit $36,5 \mathrm{vol} \%$, leukosit $4800 / \mathrm{mL}$, trombosit 157.000/mL. SGOT $35 \mathrm{U} / \mathrm{L}$, SGPT $6 \mathrm{U} / \mathrm{L}$, ureum $29 \mathrm{mg} / \mathrm{dL}$, kreatinin $0,6 \mathrm{mg} / \mathrm{dL}$.

Enam jam perawatan di ICU, kaki terba dingin, denyut arteri dorsalis pedis lemah, pasien diberikan heparin 25 unit $/ \mathrm{kgBB} / \mathrm{jam}$. Pada hari kedua pasca PTBV, bayi tidak sesak, ikterik, kedua kaki sianosis dan dingin serta denyut arteri dorsalis pedis lemah, tanda vital stabil. Hasil laboratorium hemoglobin 18,5 $\mathrm{g} / \mathrm{dL}$, hematokrit $54,1 \mathrm{vol} \%$, leukosit $20.500 / \mathrm{mL}$, trombosit $135.000 / \mathrm{mL}$, masa protrombin (PT) 18,3 detik (kontrol 13,4), masa protrombin teraktifasi (aPTT) 48,7 detik (kontrol 30,5), albumin 3,5 g/dL, SGOT $21 \mathrm{U} / \mathrm{L}$, SGPT $13 \mathrm{U} / \mathrm{L}$, bilirubin total 10,02 
$\mathrm{mg} / \mathrm{dl}$, bilirubin direk $0,91 \mathrm{mg} / \mathrm{dl}$, bilirubin indirek $9,11 \mathrm{mg} / \mathrm{dl}$. Dosis heparin dinaikkan menjadi 50 unit/ $\mathrm{kgBB} / \mathrm{jam}$ dan antibiotik diganti menjadi meropenam IV $80 \mathrm{mg} / 8 \mathrm{jam}$.

Pada hari kelima pasca PTBV, bayi tidak sesak, tidak demam, sianosis tidak ada, pulsasi arteri dorsalis pedis baik, tanda vital stabil. Bunyi jantung I normal, bunyi jantung II tunggal, terdengar bising ejeksi sistolik derajat 3 dari 6 skala di sela iga - 2 garis sternal kiri, tidak terdapat irama derap. Pemeriksaan ekokardiografi paska PTBV didapatkan dilatasi atrium kanan, regurgitasi trikuspid ringan (PG: $40 \mathrm{mmHg}$ ), hipoplastik ringan-sedang ventrikel kanan, aliran pulmonal baik, DAP kecil $2 \mathrm{~mm}$, terdapat PFO dan fungsi sistolik ventrikel kiri baik, diberikan pengobatan dengan sefadroksil oral $2 \times 250 \mathrm{mg}$, ferosemid oral $2 \times$ $4 \mathrm{mg}, \mathrm{KSR}^{\circledR}$ oral $1 \times 75 \mathrm{mg}$, digoksin oral $2 \times 20 \mathrm{mg}$, heparin dihentikan. Pasien diperbolehkan pulang keesokan harinya dan dianjurkan kontrol teratur.

\section{Diskusi}

Stenosis pulmonal kritis adalah suatu kedaruratan pada neonatus akibat obstruksi berat pada katup pulmonal sehingga aliran darah ke paru dari ventrikel kanan sangat sedikit akibatnya terjadi peningkatan tekanan ventrikel kanan, terjadi pirau kanan ke kiri melalui atrium septum dan aliran darah paru tergantung dari ada tidaknya DAP. ${ }^{3-5}$

Stenosis pulmonal kritis jarang terjadi, diperkirakan prevalens sekitar 0,58 per 10.000 kelahiran hidup. Perbandingan antara laki-laki dan perempuan sama. ${ }^{6}$ Etiologi dari stenosis pulmonal diperkirakan akibat adanya proses inflamasi pada saat pembentukan katup jantung, yang dicurigai berhubungan dengan infeksi rubela. $^{7}$

Manifestasi klinis yang yang pada SPK adalah sianosis akibat adanya pirau dari kanan ke kiri lewat DSA/patent foramen ovale (PFO). Obstruksi tersebut menyebabkan terjadinya peningkatan tekanan di proksimal dari sumbatan tersebut (hipertrofi ventrikel kanan). Derajat hipertrofi bergantung dari tekanan di ventrikel kanan. ${ }^{4}$

Bayi yang menderita SPK pada umumnya lahir cukup bulan dan tidak terdapat gangguan pertumbuhan selama kehamilan. Gejala sianosis timbul berapa jam sampai berapa hari setelah lahir, hal ini tergantung aliran duktus apakah cukup atau tidak. Sianosis mungkin terjadi hilang timbul terutama saat bayi menangis atau minum susu. Sianosis berat dapat juga terjadi dan menetap akibat penutupan tiba-tiba duktus arteriosus. Bayi dengan sianosis berat dapat disertai dengan asidosis dan pernapasan dalam sebagai kompensasi untuk mengkoreksi asidosis. Pada sianosis berat mukosa dan ujung jari terlihat pucat dan dingin dikarenakan rendahnya curah jantung dan vasokonstriksi perifer. Gejala lain hiperpneu, hepatomegali yang timbul akibat gagal jantung kanan dan jari tabuh yang timbul pada bayi di atas 4 bulan. Pemeriksaan auskultasi ditemukan bising ejeksi sistolik pada garis sternal kiri. ${ }^{7-9}$

Pasien lahir cukup bulan, tanpa gangguan pertumbuhan selama masa fetus. Keluhan sianosis mulai terlihat saat pasien usia 2 hari, terutama saat bayi menangis dan minum susu dan belum ditemukan adanya tanda-tanda gagal jantung kanan maupun jari tabuh. Menurut kepustakaan gagal jantung umumnya terjadi pada usia 4 bulan. Pemeriksaan fisis ditemukan bising ejeksi sitolik yang terdengar paling keras di daerah katup pulmonal.

Pemeriksaan EKG pada stenosis pulmonal ringan biasanya normal. Pada keadaan stenosis berat dapat ditemukan tanda-tanda hipertrofi ventrikel kanan (deviasi aksis ke kanan, gelombang $\mathrm{R}$ tinggi di $\mathrm{V}_{4} \mathrm{R}$ atau $\mathrm{V}_{1}$, disertai gelombang $S$ yang dalam di $\mathrm{V}_{6}$ ). Ekokardiografi dilakukan untuk menilai lokasi kelainan, mencari kelainan jantung kongenital lainnya, menilai derajat obstruksi dan mengukur PG. Pressure gradient kurang dari $50 \mathrm{mmHg}$ dianggap ringan, $\mathrm{PG}$ 50-79 $\mathrm{mmHg}$ dianggap sedang dan PG lebih dari 80 $\mathrm{mmHg}$ dianggap berat. Pemeriksaan foto Rongent toraks umumnya ditemukan ukuran jantung yang normal disertai segmen pulmonal yang menonjol. Kardiomegali bisa ditemukan bila telah terdapat gagal jantung kongestif. ${ }^{4,10}$ Pemeriksaan ekokardiografi fetal dapat membantu dalam memperkirakan terjadinya SPK saat kehamilan dengan cara mengukur anulus katup trikuspid, ratio anulus katup trikuspid dan mitral serta ada tidaknya regurgitasi trikuspid. ${ }^{6}$

Pada kasus yang dilaporkan dari pemeriksaan radiologik toraks tidak didapatkan pembesaran jantung. Pada EKG didapatkan adanya dilatasi atrium kanan dan hipertrofi ventrikel kanan. Ekokardiografi memperlihatkan adanya SPK dengan PG $81 \mathrm{mmHg}$, DSA sekundum sedang dengan pirau kanan ke kiri dan DAP sedang yang panjang.

Tata laksana SPK meliputi terapi medikamentosa, tindakan non invasif dan tindakan bedah. Pada SPK 
pemberian prostaglandin $\mathrm{E}_{1}\left(\mathrm{PGE}_{1}\right)$ dengan dosis 5 sampai 10 nanogram $/ \mathrm{kgBB} /$ menit diperlukan untuk mempertahankan terbukanya PDA sehingga terjadi aliran darah pulmonal yang adekuat. ${ }^{4,8,11}$ Pemberian $\mathrm{PGE}_{1}$ diberikan sesegera mungkin, terus menerus selama dan setelah tindakan pembukaan katup pulmonal. Pemantauan klinis dan saturasi oksigen sistemik dilakukan selama penurunan dosis $\mathrm{PGE}_{1}$ secara bertahap sampai penghentian untuk menilai apakah ventrikel kanan sanggup sebagai satu-satunya sumber aliran darah ke paru. Pemberian dopamin atau dobutamin intravena (5-10 mikrogram $/ \mathrm{kgBB} /$ menit) diperlukan untuk memperbaiki fungsi sistolik ventrikel kanan dan memperbaiki aliran darah ke ginjal. Bayi harus distabilisasi secepat mungkin dan disiapkan untuk dilakukan balloon pulmonary valvuloplasty. Pemberian antibiotik profilaksis diperlukan untuk mencegah endokarditis bakterialis saat dilakukan tindakan. ${ }^{11}$

Bayi mendapatkan $\mathrm{PGE}_{1}$, diturunkan secara bertahap selama 4 hari. Dopamin diberikan walaupun belum terdapat gagal jantung kogestif untuk mempertahankan sirkulasi paru pasca PTBV. Heparin diberikan untuk mencegah terjadinya trombus. Hari kedua paska PTBV dosis heparin ditingkatkan karena kedua kaki masih sianosis dan dingin serta denyut arteri dorsalis pedis lemah. Pemberian antibiotik juga diberikan pada kasus ini. Tata laksana telah sesuai dengan panduan.

\section{Valvuloplasti balon katup pulmonal}

Tindakan pembebasan penyempitan katup pulmonal dengan metode transkateter pertama kali dilakukan pada awal tahun 1950 oleh Rubio-Alverez dkk. ${ }^{4}$ Mereka menggunakan kateter uretral dengan kawat pemotong katup pulmonal yang mengalami stenosis. Kan $d k k^{12}$ tahun 1982, melaporkan tehnik baru untuk membebaskan obstruksi pada katup pulmonal dengan menggunakan balon. Penelitian yang dilakukan oleh Bilkis AA, $d k k$ terhadap 22 bayi usia 4 sampai 90 hari yang dilakukan PTBV, menyimpulkan bahwa PTBV merupakan prosedur yang utama bagi neonatus dengan SPK. ${ }^{13}$

Indikasi untuk dilakukan PTBV sama dengan valvotomi pulmonal secara bedah, yaitu stenosis pulmonal sedang-berat dengan perbedaan tekanan lebih dari $50 \mathrm{mmHg}$ dengan indeks jantung normal. ${ }^{4}$ Komplikasi yang dapat terjadi pasca PTBV adalah perforasi jantung dengan tamponade jantung, hiperkontraktilitas otot di infudibulum (hipertrofi), terjadinya insufisiensi katup trikuspid berat, trombosis, perdarahan serta dapat terjadi kematian. Komplikasi ringan dapat berupa aritmia dan hipoksemia., ${ }^{4,7}$

Indikasi PTBV adalah stenosis pulmonal berat, PG lebih dari $50 \mathrm{mmHg}$ sehingga PTBV dilakukan sesegera mungkin. Tindakan PTBV pada kasus ini berhasil membuka katup pulmonal sehingga terjadi penurunan PG dari $81 \mathrm{mmHg}$ menjadi $45 \mathrm{mmHg}$. Komplikasi yang serius tidak terjadi pada pasien ini, kecuali hanya beberapa episode desaturasi Tindakan PTBV pada kasus stenosis pulmonal kritis baru pertama kalinya dilakukan di Indonesia. Pada saat ini prosedur PTBV paling banyak dilakukan, karena relatif sederhana, efektif dan murah. Penyempitan berulang (restenosis) pasca PTBV dilaporkan sekitar 8-10\%. ${ }^{4}$

Pasien perlu dipantau untuk menilai pertumbuhan ventrikel kanan. Jika ventrikel kanan ukurannya normal, tindakan selanjutnya adalah penutupan DSA dengan Amplatzer, dan jantung pasien berfungsi sebagai dua ventrikel terpisah seperti jantung normal. Jika ventrikel kanan tidak tumbuh sempurna, masih hipoplasia sedang, maka tindakan selanjutnya adalah membuat satu setengah ventrikel dengan jalan melakukan BCPS (bidirectional cavo-pulmonary shunt), penutupan DSA. Jika ventrikel kanan sangat kecil (hipoplasia berat), maka pasien merupakan kandidat ventrikel tunggal dengan melakukan operasi Fontan.

\section{Kesimpulan}

Tindakan PTBV harus segera dilakukan pada stenosis pulmonal kritis untuk menyelamtkan jiwa pasien. Penyempitan berulang pernah dilaporkan pada sebagian kecil kasus maka pemantauan pasca dilatasi harus dilakukan secara serial.

Prognosis pasien ditentukan oleh pertumbuhan ventrikel kanan pasca PTBV, apakah pasien nanti kandidat biventrikel, satu setengah ventrikel atau ventrikel tunggal.

\section{Daftar Pustaka}

1. Soeroso S, Sastrosoebroto H. Penyakit jantung bawaan non sianotik. Dalam: Sastroasmoro S, Madiyono B, penyunting. Buku ajar kardiologi anak, Jakarta: Binarupa Aksara; 1994. h. 194-233. 
2. Djer MM. Interventional pediatric cardiology in Indonesia: a multicenter experience. Disampaikan pada KONIKA XIII; 2005 Juli 4-7; Bandung.

3. Jacobs ML. Pulmonary stenosis. Diunduh dari: www.dlib-medical online library-English Articles-Oxford texbook of surgery.htm. Diakses tanggal 4 Mei 2007.

4. Rao PS. Pulmonary stenosis, valvar. Diunduh dari: www.emedicine.htm. Diakses tanggal 4 Mei 2007.

5. Fiore AC, Jureidini S, Keenan W, Johnson RG. Cardiac surgery in the newborn: Improve results in the current era. Diunduh dari: www. Cardiac surgery in the newborn.htm. Diakses tanggal 4 Mei 2007

6. Paterson RE, Levi DS, Williams RJ, Lai WW, Sklansky MS, Drant S. Echocardiographic predictors of outcome in fetus with pulmonary atresia with intact ventricular septum. Journal of the American Society of Echocardiography 2006; 19:1393-400.

7. Riopel DA. Pulmonary valve atresia with intact ventricular septum. Dalam: McMillan JA, penyunting. Oski’ Pediatrics principles and practice. Edisi ketiga. London: A Wolters Kluwer Company; 1999. h. 1365-72.
8. Park MK. Pediatric cardiology for practitioners. Edisi keempat. London: St. Louis: Mosby Inc; 2002. h. 209-42

9. Zipes. Braunwald's Heart Disease: A textbook of Cardiovascular Medicine. Edisi ketujuh. London: Saunders; 2005. h. 232-74

10. Congenital Heart Disease. Diunduh dari: www. PS/ congenital heart disease.htm. Diakses tanggal 4 Mei 2007.

11. Cheatham JP. Pulmonary stenosis. Dalam: Garson A, Bricker JT, Fisher DJ, Neish SR, penyunting. The science and practice of pediatric cardiology. Edisi kedua. London: Williams \& Wilkins; 1998. h. 1207-56.

12. Kan JS, White RI, Mitchell SE, Gardner TJ. Percutaneous balloon valvuloplasty: A new method for treating congenital pulmonary-valve stenosis. N Engl J Med 1982; 307:540-2.

13. Bilkis AA, Alwi M, Hasri S, Haifa AL, Geetha K, Law HI. Critical Pulmonary stenosis in infants and neonates in era of interventional cardiology. Asian Cardiovasc Thorac Ann 1999; 7:40-2. 